\title{
Functional Independence of Children With Myelomeningocele: Is It Associated With the Informal Caregivers' Burden? 访
}

\author{
Karen Negrão Cavalari a , Pedro Tadao Hamamoto Filho b,*, Silvia Maria Caldeira a , \\ Helio Rubens de Carvalho Nunes ${ }^{b}$, Fernanda Maria Alves Lima ${ }^{a}$, Marla Andréia Garcia de Avila ${ }^{a}$ \\ a Department of Nursing, Botucatu Medical School, UNESP - Univ Estadual Paulista, Brazil \\ ${ }^{b}$ Department of Neurology, Psychology and Psychiatry, Botucatu Medical School, UNESP - Univ Estadual Paulista, Brazil
}

\section{A R T I C L E I N F O}

\section{Article history:}

Received 5 January 2017

Revised 11 July 2017

Accepted 11 July 2017

\section{Keywords:}

Myelomeningocele

Functional independence

Caregivers' burden

\begin{abstract}
A B S T R A C T
Purpose: This study aims to evaluate the association between the functional independence of children after postnatal spinal dysraphism correction and informal caregivers' burden.

Design and Methods: This is a cross-sectional study conducted in a child neurosurgery clinic at a University hospital. We included informal caregivers of children between six months and seven-and-a-half years old who were operated on for spinal dysraphism correction due to myelomeningocele. Functional independence was assessed using the Pediatric Evaluation of Disability Inventory (PEDI). Caregivers' burden was assessed through the Caregiver Burden Scale (CBS).

Results: Twenty-six caregivers were assessed, all mothers, aged 18-42 years. Five provided child care and engaged in paid work. Regarding functional independence, $23.1 \%$ of the children were classified as needing supervision, $23.1 \%$ moderate assistance, $42.3 \%$ maximal assistance, and $11.5 \%$ total assistance. Median value for the overall CBS was 27.0 (22.0-53.0). The mean global CBS score was 1.42 and the mean PEDI score was 1.95. Correlations between PEDI and CBS scores were very close to zero.

Conclusions: We found no association between the functional independence of children with myelomeningocele from 0 to 7 years old and the burden of informal caregivers.

Practice Implications: The effect of functional independence of children with myelomeningocele may be balanced by the caregivers' resilience so that caregivers' burden is not dependent upon the child's independence.
\end{abstract}

(c) 2017 Elsevier Inc. All rights reserved.

\section{Introduction}

Spina bifida represents up to two thirds of neural tube defects that occur prenatally (Pitkin, 2007) and clinical manifestations depend on the severity of the exposed neurologic elements: spina bifida occulta is generally asymptomatic, while myelomeningocele may cause severe disabilities (Bowman et al., 2009). The etiologic mechanisms are not fully understood, but appear to be related to an interaction between genetic and environmental factors, such as folate deficiency and valproic acid exposure (Atta et al., 2016; Copp, Stainer, \& Greene, 2013). Surgical closure should be performed within the first $24 \mathrm{~h}$ after birth in order to prevent infection. Recently, fetal surgery has increasingly become an option for spina bifida repair as it may reduce the occurrence of

\footnotetext{
is KNC was funded by FAPESP - Fundação de Amparo à Pesquisa do Estado de São Paulo (14/26225-1)

* Corresponding author: Pedro Tadao Hamamoto Filho.

E-mail address: pthamamotof@hotmail.com (P.T. Hamamoto Filho).
}

associated hydrocephalus (Adzick et al., 2011), but it is not yet widely used, especially in developing countries.

Myelomeningocele is a defect in the neural tube closure determining an opened spinal cord covered by meningeal sac (spina bifida cystica) or exposed (spina bifida aperta) (Copp et al., 2015). It is the most severe type of spina bifida and is responsible for several disabilities and healthcare needs. The disease may present new symptoms and disabilities during the lifetime: motor impairment, urinary and bowel incontinence, scoliosis, chronic pain, and shunt dysfunction in hydrocephalus (Piatt Jr., 2010). Therefore, patients require a range of healthcare centers, professionals, and technologies. They may have lengthy hospitalizations, a need for physiotherapy, nursing procedures, and a variety of surgical procedures. Therefore, myelomeningocele is of major importance for healthcare providers and health systems (World Health Organization, 2005).

Myelomeningocele is also a concern for social institutions because of patients' special needs, especially during their education. However, the family faces the greatest challenges. The psychosocial problems occasioned by a dependent family member may distort the entire family functioning (Figueiredo, Sousa, \& Gomes, 2016; Rodríguez-Sánchez et 
al., 2011). Moreover, one family member, usually the mother, takes on most of the responsibility for the child's care. They are the informal caregivers. Sometimes the informal caregiver may have neither the formal knowledge for completing technical tasks (like urinary catheterization) nor psychological support (Macedo, da Silva, Paiva, \& Ramos, 2015).

Different areas of the caregivers' lives are affected by their caregiver role: social, psychological, and economic domains are radically changed (Rofail, Maguire, Kissner, Colligs, \& Abetz-Webb, 2013). Consequently, symptoms of anxiety and depression are very common among caregivers of children with myelomeningocele and their quality of life may be severely impaired (Malm-Buatsi et al., 2015; Valença, Menezes, Calado, \& Cavalcanti, 2012).

Despite the many studies on the burden on caregivers of children with myelomeningocele, few have tried to understand whether the burden is associated with the degree of functional independence of the children; that is, do independent children place fewer burdens on their caregivers?

\section{Methods}

Ethics Statement

The local Institutional Ethics Committee approved the project and all the participants signed the informed consent.

\section{Study Design}

This is a descriptive cross-sectional study. It was conducted at the Pediatric Neurosurgery clinic at a major medical school tertiary hospital in Brazil responsible for treating up to 1.5 million people. All patients attending the clinic from March 2015 to February 2016 were selected. Inclusion criteria were patients with repaired myelomeningocele aged 6 months to 7.5 years with informal caregivers who self-reported as the main caregiver without financial support for this role. Exclusion criteria were other neural tube defects (such as cranial meningocele), patients with associated brain malformations other than those expected from myelomeningocele, and caregivers aged younger than 18 years old.

\section{Data Collection}

Informal caregivers were asked to answer socio-demographic questions, the Pediatric Evaluation of Disability Inventory (PEDI), and the Caregiver Burden Scale (CBS).

The PEDI assesses children's functional performance (Haley et al., 1992). We used a Portuguese version, adapted to Brazilian sociocultural characteristics (Mancini, 2005). This inventory is divided into three parts: assessment of the functional skills of the child, quantity of help the adult gives to the child, assessment of the modifications to the house to enable the child to perform tasks. In this study, we used only the second part. Therefore, we asked caregivers about the children's need for assistance in performing 20 tasks: self-care ( 8 items, e.g. eating and toileting), mobility ( 7 items, e.g. chair and toilet transfers), and social function ( 5 items, e.g. peer play and safety). The answers ranged from independent (5 points), needs supervision, minimal assistance, moderate assistance, and maximal assistance, to total assistance ( 0 points). In total, scores can range from 0 to 100.

The CBS instrument was translated into Portuguese and validated for Brazil (Medeiros, Ferraz, Quaresma, \& Menezes, 1998). It has 22 questions divided in five domains: general strain (e.g. Do you find yourself facing purely practical problems in the care of your relative that you think are difficult to solve?), isolation (e.g. Do you avoid inviting friends and acquaintances home because of your relative's problem?), disappointment (e.g. Have you a feeling that life has treated you unfairly?), emotional involvement (e.g. Are you sometimes ashamed of your relative's behaviour?), and environment (Does the physical environment make it troublesome for you taking care of your relative?). Answers range from never (1), rarely (2), sometimes (3) to often (4). Caregivers with a CBS score higher than 44 were considered overburdened.

Cronbach alpha was used to assess internal reliability of the instruments. In this sample, $\alpha=0.98$ for the PEDI II and 0.88 for the CBS.

\section{Statistical Analysis}

For statistical purposes, we considered type I and II errors of 0.05 and 0.10 , respectively, without potential confounders. We assumed that the relationship between the scores of the CBS and PEDI is a direct linear correlation with a value of 0.6 . We determined the necessary sample size to be 26 children from 26 informal caregivers. To test the relationship between the scores from CBS and PEDI we used the Spearman correlation. Values were considered statistically different when $p<0.05$. The Statistical Package for Social Sciences (SPSS version 15.0) was used to perform the analyses.

\section{Results}

We included 26 informal caregivers of 26 children. All caregivers were the mothers of the children. Their median age was 29 years. Twenty-one (81\%) did not have paid work. Among the children, $76 \%$ (16) were female and the median age was 2.6 years. Table 1 summarizes the demographic data. Regarding functional independence, 23.1\% (6) were classified as needing supervision, $23.1 \%$ (6) moderate assistance, 42.3\% (11) maximal assistance, and 11.5\% (3) total assistance.

On the PEDI II, median global dependence score was 28; for self-care, the median score was $10(0.0-40.0)$; for mobility it was $7(0.0-35.0)$, and for social function it was $11.5(0.0-25.0)$. Table 2 shows the profile of the sample according to the child's dependence (measured by the PEDI II) and caregiver burden (measured by the CBS). Dependence on the caregiver is greatest in the mobility domain, with an average of 1.72 for each question ( $\mathrm{Cl} 0.98-2.46)$ and lowest in the social function, with an average of 2.48 (CI: 1.78-3.19). Median value for the overall CBS was 27.0 (22.0-53.0), for general tension it was 10.0 (8.0-21.0),

Table 1

Socio-demographic and clinical data of children with myelomeningocele and their informal caregivers.

\begin{tabular}{|c|c|c|}
\hline Variable & $N$ & $\%$ \\
\hline \multicolumn{3}{|l|}{ Caregiver } \\
\hline \multicolumn{3}{|l|}{ Sex } \\
\hline Female & 26 & 100 \\
\hline \multicolumn{3}{|l|}{ Family relationship } \\
\hline Mother & 26 & 100 \\
\hline \multicolumn{3}{|l|}{ Marital status } \\
\hline Married and living with a partner & 21 & 81 \\
\hline Widowed, separated, or single & 05 & 19 \\
\hline \multicolumn{3}{|l|}{ Paid work } \\
\hline Yes & 05 & 19 \\
\hline No & 21 & 81 \\
\hline Age & $29^{\mathrm{a}}$ & $(18-42)^{\mathrm{b}}$ \\
\hline Daily care hours & $19^{\mathrm{a}}$ & $(16-24)^{\mathrm{b}}$ \\
\hline \multicolumn{3}{|l|}{ Children } \\
\hline \multicolumn{3}{|l|}{ Sex } \\
\hline Female & 16 & 76 \\
\hline Male & 05 & 24 \\
\hline Neurogenic bowel & 07 & 27 \\
\hline Neurogenic bladder & 15 & 58 \\
\hline Age & $2.6^{\mathrm{a}}$ & $(0.5-7.0)^{\mathrm{b}}$ \\
\hline \multicolumn{3}{|l|}{ Functional independence } \\
\hline Supervision & 06 & 23.1 \\
\hline Moderate supervision & 03 & 11.5 \\
\hline Maximum supervision & 11 & 42.3 \\
\hline Full supervision & 06 & 23.1 \\
\hline
\end{tabular}

\footnotetext{
a Median.
}

b Range. 
Table 2

Scores of $\mathrm{PEDI}^{\mathrm{a}}$ and $\mathrm{CBS}^{\mathrm{b}} \mathrm{c}$ dimensions for caregivers of children with meningomyelocele.

\begin{tabular}{|c|c|c|c|c|}
\hline Dimensions & Mean $^{\mathrm{c}}$ & Standard deviation & \multicolumn{2}{|c|}{$\begin{array}{l}\text { Confidence } \\
\text { interval } \\
95 \%\end{array}$} \\
\hline \multicolumn{5}{|l|}{ PEDI II } \\
\hline Self-care & 1.81 & 1.48 & 1.22 & 2.41 \\
\hline Mobility & 1.72 & 1.83 & 0.98 & 2.46 \\
\hline Social funcion & 2.48 & 1.73 & 1.78 & 3.19 \\
\hline PEDI II global & 1.95 & 1.59 & 1.31 & 2.59 \\
\hline \multicolumn{5}{|l|}{ CBS } \\
\hline General strain & 1.50 & 0.57 & 1.26 & 1.73 \\
\hline Isolation & 1.38 & 0.73 & 1.09 & 1.68 \\
\hline Disappointment & 1.34 & 0.47 & 1.15 & 1.53 \\
\hline Emotional involvement & 1.12 & 0.28 & 1.00 & 1.23 \\
\hline Environment & 1.73 & 0.77 & 1.42 & 2.04 \\
\hline CBS global & 1.42 & 0.43 & 1.25 & 1.60 \\
\hline
\end{tabular}

a Pediatric evaluation of disability inventory.

b Caregiver burden scale.

c These data refer to the mean score for the questions of the assessed domain.

for isolation 3.0 (3.0-12.0), for disappointment 6.0 (5.0-14.0), for emotional involvement 3.0 (3.0-6.0), and for environment 5.0 (3.0-11.0). Analyzing the mean score for each question (see Table 2 ), the environment domain showed the greatest burden, with a mean of $1.73(\mathrm{CI}$ 1.42-2.04) and the emotional involvement domain the lowest burden, with a mean of 1.12 (CI 1.0-1.23). Table 3 shows that the caregiver burden is not dependent upon the functional dependence of the child, as the $p$-value was higher than 0.05 in all tested correlations with correlations very close to zero. Also, a Spearman correlation was performed to test potential confounders such as the children's age, but the relations were not significant.

\section{Discussion}

Children with myelomeningocele were cared for by their mothers, corroborating the literature documenting that mothers continue to be the primary caregivers (Figueiredo et al., 2016; Macedo et al., 2015; Rofail et al., 2013; Valença et al., 2012). In a recent review, mothers were the primary caregivers (up to $100 \%$ in samples varying from 15 to 787 caregivers) (Macedo et al., 2015).

We found that $81 \%$ of mothers had a partner. Findings are inconsistent pertaining to the impact of partner support on the caregiver's burden of care. (Holmbeck \& Devine, 2010). An American study, which included 84 caregivers of children and young people with spina bifida, showed higher scores of anxiety and depression among mothers with a partner (Malm-Buatsi et al., 2015). Another Brazilian study that assessed the burden of 43 caregivers of children and adolescents with myelomeningocele also showed higher burden scores in those who were living with a partner (Valença et al., 2012). However, Rofail et al. (2013) conducted a phenomenological analysis of 25 articles from 1976 to 2010 and concluded that having a partner might be beneficial for coping with the disease and sharing care. Furthermore, we need to consider the relationship of the parents before the child's birth and the ability to develop resilient care. Future studies should assess whether caregivers with family support experience less burden. It should be considered that not only the partner but also a grandmother could play an important role.

In our study, $81 \%$ of the mothers did not have paid work, and were dedicated exclusively to child care and other activities of home and family. These data are similar to other studies (Figueiredo et al., 2016; Macedo et al., 2015; Rofail et al., 2013; Valença et al., 2012). The lack of a support system for caregivers who need to give up paid work in order to care for the child is one of the health system's weaknesses (Neves, Pietrovski, \& Claudino, 2015) and is still a neglected topic.

Regarding the burden perceived by the caregiver, we found that $7.6 \%$ of caregivers were overburdened based their CBS score. The overall average score was 1.42 and scores were highest in the domains of environment (1.73) and general tension (1.5). Our research corroborates a Brazilian study (Valença et al., 2012), which considered caregivers of children from 0 to 15 years, and identified a global CBS average of 2.2, with higher burden scores in the fields general tension and environment ( 2.5 and 2.6. respectively). The scores were higher in caregivers of children aged $0-15$ years, signaling the importance of action to minimize the burden on these families shortly after birth. In both studies caregivers acknowledged difficulties regarding the environmental accessibility (e.g. to take a bus or to climb stairs with their children). Regarding general tension, they identified the deprivation of their private life, which resulted in their feelings of fatigue and health problems.

Although the children in the study presented high levels of dependence on the caregiver, predominantly full and maximum assistance, we found no association between the level of dependency and the burden on the caregiver. One possible explanation is the median age of the children (2.6 years old). In this age group, children are dependent on their parents in both the presence and absence of chronic health conditions. Many children do not yet attend school and have few social activities. Research that examined caregivers of children with cerebral palsy found that the burden on caregivers of children with less motor impairment was higher than for the most seriously impaired children. The authors believe that a likely explanation may be that children with milder impairments have greater independence and participation in social life than children with severe impairments. Their participation in social life may not meet their expectations, thereby causing frustration. (Camargos, Lacerda, Viana, Pinto, \& Fonseca, 2009).

Caregivers, while playing a key role, are often considered as the child's parents, and are not recognized as people who are going through a process of suffering and who need technical and emotional preparedness to exercise care. It is important to include the family in the care plans, to share their knowledge and to teach them some necessary skills. In this way, parents may feel more confident in the role of caregivers. This care guidance promotes family and caregiver empowerment to those who are active in the child's care (Amador, Gomes, Reichert, \& Collet, 2013). Hospitals and healthcare institutions should provide an important public policy initiative with specific attention to caregivers, identifying the risk factors for their health and taking action to identify and minimize their burden.

Table 3

Association between $\mathrm{PEDI}^{\mathrm{a}}$ and $\mathrm{CBS}^{\mathrm{b}}$ scores (Spearman correlation).

\begin{tabular}{|c|c|c|c|c|c|c|c|}
\hline & & General Strain & Isolation & Disappointment & Emotional involvement & Environment & CBS:global \\
\hline \multirow[t]{2}{*}{ PEDI II self-care } & $r$ & 0.12 & -0.08 & 0.13 & 0.18 & 0.04 & 0.13 \\
\hline & $p$ & 0.561 & 0.686 & 0.543 & 0.387 & 0.840 & 0.539 \\
\hline \multirow[t]{2}{*}{ PEDI II mobility } & $r$ & 0.03 & -0.23 & 0.03 & 0.25 & 0.02 & 0.03 \\
\hline & $p$ & 0.893 & 0.263 & 0.879 & 0.216 & 0.910 & 0.894 \\
\hline \multirow[t]{2}{*}{ PEDII social function } & $r$ & -0.02 & -0.09 & -0.14 & 0.20 & -0.06 & -0.02 \\
\hline & $p$ & 0.923 & 0.646 & 0.491 & 0.327 & 0.770 & 0.931 \\
\hline \multirow[t]{2}{*}{ PEDII: CBS global } & $r$ & 0.11 & -0.14 & 0.00 & 0.18 & 0.01 & 0.05 \\
\hline & $p$ & 0.607 & 0.481 & 0.988 & 0.388 & 0.948 & 0.794 \\
\hline
\end{tabular}

\footnotetext{
a Pediatric evaluation of disability inventory.
}

b Caregiver burden scale. 
Finally, the availability of an adapted and validated instrument for the language of interest was vital in selecting this assessment tool, but the instrument deserves greater attention. The CBS has been used to assess burden among caregivers of children with chronic diseases, but it is recommended for caregivers in general (adults, seniors, children, and adolescents). In addition, it is quite difficult for a mother or caregiver to indicate explicitly that their children cause them to feel burdened. This makes the responses on the CBS more subjective.

\section{Practice Implications}

We recommend carrying out studies with other methodological designs. Moreover, we recommend the development, adaptation, and validation of a specific instrument for evaluating the burden of caregivers with dependent children. The resilience of informal caregivers of children with chronic diseases is an interesting area of research.

\section{Conclusions}

In conclusion, the children in our study presented high levels of dependence on the caregiver (predominantly full and maximum assistance), but only $7.6 \%$ of caregivers were overburdened based their CBS score. We found no association between the functional independence of children with myelomeningocele from 0 to 7 years old and the burden of informal caregivers. These results may be explained by the low median age of the children in this sample and by the difficulty for caregivers to indicate that their children cause them to feel burdened. It will be valuable to continue with studies with parents of older children.

\section{References}

Adzick, N. S., Thom, E. A., Spong, C. Y., Brock, J. W., Burrows, M. S., Johnson, M. P., ... Farmer, D. L. (2011). A randomized trial of prenatal versus postnatal repair of myelomeningocele. New England Journal of Medicine, 364, 993-1004. http://dx.doi. org/10.1056/NEJMoa1014379.

Amador, D. D., Gomes, I. P., Reichert, A. P. S., \& Collet, N. (2013). Impact of childhood cancer for family caregivers: Integrative review. Revista Brasileira de Enfermagem, 66(2), 267-270. http://dx.doi.org/10.1590/S0034-71672013000200017.

Atta, C. A., Fiest, K. M., Frolkins, A. D., Jette, N., Prignsheim, T., St Germaine-Smith, C. Metcalfe, A. (2016). Global birth prevalence of spina bifida by folic acid fortification status: A systematic review and meta-analysis. American Journal of Public Health, 106, e24-e34. http://dx.doi.org/10.2105/AJPH.2015.302902.

Bowman, R. M., Boshnjaku, V., \& McLone, D. G. (2009). The changing incidence of myelomeningocele and its impact on paediatric neurosurgery: A review from the Children's memorial hospital. Child's Nervous System, 25, 801-806. http://dx.doi.org/ 10.1007/s00381-009-0865-z.

Camargos, A. C. R., Lacerda, T. T. B., Viana, S. O., Pinto, L. R. A., \& Fonseca, M. L. S. (2009) Assessment of the caregiver burden of children with cerebral palsy using the burden interview scale. Revista Brasileira de Saúde Materno Infantil, 9, 31-37. http://dx.doi. org/10.1590/S1519-38292009000100004

Copp, A. J., Adzick, N. S., Chitty, L. S., Fletcher, J. M., Holmbeck, G. N., \& Shaw, G. M. (2015). Spina bifida. Nat Rev Dis Primers, 1, 15007. http://dx.doi.org/10.1038/nrdp.2015.7.

Copp, A. J., Stainer, P., \& Greene, \& N.D.E. (2013). Neural tube defects: Recent advances, unsolved questions, and controversies. The Lancet Neurology, 12, 799-810. http://dx. doi.org/10.1016/S1474-4422(13)70110-8.

Figueiredo, S. V. Sousa, A. C. C. \& Gomes, I. L. V. (2016). Children with special health needs and family: implications for nursing. Revista Brasileira de Enfermagem, 69, 79-85. http://dx.doi.org/10.1590/0034-7167.2016690112i.

Haley, S. M., Coster, W. J., Ludlow, L. H., Haltiwanger, J. T., \& Andrellos, P. A. (1992). Pediatric evaluation of disability inventory: Development, standardization and administration manual. Boston, MA: Trustees of Boston University.

Holmbeck, G. N., \& Devine, K. A. (2010). Psychosocial and family functioning in spina bifida. Developmental Disabilities Research Reviews, 16, 40-46. http://dx.doi.org/10. 1002/ddrr.90.

Macedo, E. C., da Silva, L. R., Paiva, M. S., \& Ramos, M. N. P. (2015). Burden and quality of life of mothers of children and adolescents with chronic illnesses: An integrative review. Revista Latino-Americana de Enfermagem, 23, 769-777. http://dx.doi.org/10. 1590/0104-1169.0196.2613.

Malm-Buatsi, E., Aston, C. E., Ryan, J., Tao, Y., Palmer, B. W., Kropp, B. P., \& Frimberger, D. (2015). Mental health and parenting characteristics of caregivers of children with spina bifida. Journal of Pediatric Urology, 11, 65.e1-65.e7. http://dx.doi.org/10.1016/ j.jpurol.2014.09.009.

Mancini, M. C. (2005). Pediatric Evaluation of Disability Inventory (PEDI): manual of the Brazilian adapted version. Belo Horizonte: UFMG, 2005 (In Portuguese).

Medeiros, M. M. C., Ferraz, M. B., Quaresma, M. R., \& Menezes, A. P. (1998). Adaption and validation of the caregiver burden scale to Brazilian cultural milieu. Revista Brasileira de Reumatologia, 38, 193-199.

Neves, E. B., Pietrovski, E. F., \& Claudino, R. F. (2015). Quality of life and low back pain in primary caregivers of children with cerebral palsy. Cadernos Saúde Coletiva, 23, 50-56. http://dx.doi.org/10.1590/1414-462X201500010009.

Piatt, J. H., Jr. (2010). Treatment of myelomeningocele: A review of outcomes and continuing neurological considerations among adults. Journal of Neurosurgery: Pediatrics, 6, 515-525. http://dx.doi.org/10.3171/2010.9.PEDS10266.

Pitkin, R. M. (2007). Folate and neural tube defects. The American Journal of Clinical Nutrition, 85, 285S-288S Retrieved from http://ajcn.nutrition.org/content/85/1/ 285S.long.

Rodríguez-Sánchez, E., Pérez-Peñarada, A., Losada-Baltar, A., Pérez-Arechaederra, D., Gómez-Marcos, M. A., Patino-Alonso, M. C., \& García-Ortiz, L. (2011). Relationships between quality of life and family function in caregiver. BMC Family Practice, 12, 19. http://dx.doi.org/10.1186/1471-2296-12-19.

Rofail, D. Maguire, L. Kissner, M., Colligs, A. \& Abetz-Webb, L (2013). A review of the social, psychological and economic burdens experienced by people with spina bifida and their caregivers. Neurology and Therapy, 2, 1-12. http://dx.doi.org/10.1007/ s40120-013-0007-0.

Valença, M. P., Menezes, T. A., Calado, A. A., \& Cavalcanti, A. G. (2012). Burden and quality of life among caregivers of children and adolescents with meningomyelocele: Measuring the relationship to anxiety and depression. Spinal Cord, 50, 553-557. http:// dx.doi.org/10.1038/sc.2012.10.

World Health Organization (2005). Preventing chronic diseases: A vital investment. Geneva: World Health Organization Retrieved from http://www.who.int/chp/chronic disease_report/en/. 